\title{
28 Research Soure \\ Valorisation of chicken feather fibres in developing poly (vinyl chloride) biocomposites
}

\section{Soumia Touatou}

École Nationale Polytechnique: Ecole Nationale Polytechnique

Naima Belhaneche-Bensemra ( $\nabla$ naima.belhaneche@g.enp.edu.dz)

Ecole Nationale Polytechnique https://orcid.org/0000-0001-9315-8701

\section{Research Article}

Keywords: PVC, feather fibres, biocomposites, properties, water absorption

Posted Date: March 23rd, 2021

DOl: https://doi.org/10.21203/rs.3.rs-328642/v1

License: (9) This work is licensed under a Creative Commons Attribution 4.0 International License. Read Full License 


\section{Abstract}

The aim of this paper is the valorisation of fibres obtained from chicken feathers in developing new poly (vinyl chloride) (PVC) biocomposites. Feather fibres were first characterized by thermogravimetric analysis and scanning electron microscopy. Then, semi-rigid and flexible PVC biocomposites were prepared by varying the fibre $(5,10$ and $15 \mathrm{wt} \%)$ and plasticizer $(15,30,45,60 \mathrm{wt} \%)$ contents. The density, mechanical, thermal and morphological properties of the composites were investigated. The water absorption was determined at two temperatures $\left(23\right.$ and $\left.60^{\circ} \mathrm{C}\right)$. The results showed the influence of fibre and plasticizer contents on the considered properties.

\section{Introduction}

Undoubtedly, polymer composites are an important group of materials with a widespread use. The rising worldwide concept of sustainable development created a new scope for the preparation of new composite materials based on renewable resources.

Within this context, to develop bio-based products or biocomposites, one potential approach is to make composites from natural fibres. Recently, a great interest to use natural fibres as reinforcement is gaining attention. Wood fibres are the most widely used short fibres, but they can also be obtained from agro bases from different parts of the plant such as bast (jute, abaca, flax, hemp, kenaf), leaf (pineapple, sisal, screw pine), seed or fruit fibre (coir, cotton, oil palm), grasses and reeds (bamboo, sugarcane), etc. [1].

In addition to their environmental friendliness, the other advantages of natural fibres include a good stiffness and strength, with at the same time a low density compared with glass fibre. The specific Young's modulus of natural-fibre-reinforced composites is comparable with that of glass-fibre composites. Natural-fibre-reinforced composites have good lightweight construction potential and show positive break behaviour, i.e. they break without rough edges and the components do not splinter [2].

In the field of using natural fibres in polymer composites, chicken feather fibres have attracted much attention. Chicken feathers biomass, an available waste of the poultry industry, can be a renewable resource of natural fibres. This will allow developing successful applications for poultry feather in composite making. Indeed, inappropriate disposal of these wastes causes environmental pollution.

Chicken feathers are approximately $91 \%$ protein (keratin), $1 \%$ lipids and $8 \%$ water [3]. Keratins are highly specialized fibrous proteins. They are resistant to physical and chemical environmental factors. They are insoluble in water, weak acids and alkalis, organic solvents, and are insensitive to the attack of common proteolytic enzymes such as trypsin or pepsin [4].

Feather fibre is the product from clean sanitized feathers after removal of the quill. It has a crystalline melting point of ca. $240^{\circ} \mathrm{C}$ [5]. The semi-crystalline and cross-linked structure in keratin feather fibre results in a polymer with a relatively high elastic modulus of approximately $3.4-5 \mathrm{GPa}$ [6]. Tesfaye et al. 
[7] measured the diameter of chicken feathers fractions. The mean diameters of the chicken feather barbules and barb were respectively $4.93 \mu \mathrm{m}$ and $46.65 \mu \mathrm{m}$.

The high melting and degradation temperature of the poultry feather fibre makes it a good agricultural additive to be utilised in traditional polymers processed at high temperature [8]. Chicken feather fibres were used as reinforcement for polyethylene [8-10], polypropylene [11], poly (lactic acid) [12, 13], poly (methyl methacrylate) [14, 15], chitosan-starch [16] and soybean oil [17].

In this paper, chicken feather fibres (CFF) were compounded with poly (vinyl chloride) (PVC) resin to prepare bio-based composites. Chicken feathers are a renewable biomass that would be interesting to valorise. The recycling of feather waste allows the preparation of new materials within a perspective of eco-design or sustainable development, and the processing of poultry waste. It will also prevent wasting a useful material and reduce the use of fossil thermoplastics.

PVC is an important thermoplastic material because of its versatility and low cost [18]. It is usually reinforced with inorganic materials such as glass fibres, calcium carbonate, and talc. However, these types of fillers are characterized as high density materials which might increase the overall density of the composite materials [19].

The aim of this work is to make a blend of conventional and renewable resources, leading to a product that is partially renewable, and then to study the properties of the obtained materials.

\section{Experimental}

\section{Materials}

The chicken feathers were cleaned according to a process patented by the USDA [20].They were grounded for $3 \mathrm{~min}$ by using a grinder KIKA-WERKE type M20 to separate the fibres from the quill. A second grinding step was performed for $5 \mathrm{~min}$ on Waring commercial grinder to obtain fibres with lengths inferior to $4 \mathrm{~mm}$.

Commercial PVC (K value $=71.5-72.9)$ type SE-1300 from Shintech Inc. USA was used as received. Diisodecyl phthalate (DIDP) from Société Générale des Plastifiants (General Society of Plasticizers) (Tunisia) was used as plasticizer. Calcium-zinc (Ca-Zn) complex and epoxidized soybean oil, respectively, from Betaquimica (Spain) and Henkel (Germany) were used as thermal stabilizers while stearic acid from SO.G.I.S.SPA (Italy) was used as lubricant.

\section{Biocomposites preparation}

The additives used in the preparation of the various formulations were DIDP at a level of $15,30,45$ and $60 \mathrm{wt} \%$, Ca-Zn complex (5 wt\%), epoxidized soybean oil (5 wt\%) and stearic acid (2 wt\%).

PVC and additives were first mixed in a two-roll mill at $140^{\circ} \mathrm{C}$ until gelation. Then, fibres were introduced and mixed with the matrix for about $15 \mathrm{~min}$ at 5,10 and $15 \mathrm{wt} \%$. The fibre content was extended to 20 
and $25 \mathrm{wt} \%$ for the formulations with $60 \mathrm{wt} \%$ of DIDP. Then, the obtained blends were melt compressed at $170^{\circ} \mathrm{C}$ under a pressure of $300 \mathrm{kN}$ during $5 \mathrm{~min}$, save for the formulations at $15 \mathrm{wt} \%$ of DIDP which were pressed at $160^{\circ} \mathrm{C}$. The obtained plates were $2 \mathrm{~mm}$ thick.

The formulations were designated by a number corresponding to the plasticizer content, followed by a number indicating the fibre content. For example, PVC having $15 \mathrm{wt} \%$ of DIDP and $5 \mathrm{wt} \%$ of CFF was designated by $15 / 5$.

\section{Samples Characterization}

\section{Density analysis}

The density was determined by using the pycnometer method. All the reported results are averages of five measurements for each blend composition.

\section{Water Absorption analysis}

Water uptake in composites was determined by immersing weighed amounts of specimens in distilled water at $23 \pm 2^{\circ} \mathrm{C}$. After $24 \mathrm{~h}$ of immersion, samples were removed from water and wiped with filter paper and weighed again.

Furthermore, immersion of the composites in distilled water at $60^{\circ} \mathrm{C}$ for 30 min and 24 hours was performed.

The water uptake $(\Delta M)$ was calculated according to equation (1).

$$
\Delta \mathrm{M}(\%)=\frac{(\mathrm{M} 1-\mathrm{M} 0)}{\mathrm{M} 0} \times 100
$$

Where $M_{0}$ is the initial mass sample and $M_{1}$ is the mass of the sample after immersion.

\section{Tensile testing}

Tensile properties were measured using Zwick/Roell testing machine with a crosshead rate maintained at $100 \mathrm{~mm} / \mathrm{min}$. Five measurements were conducted for each blend composition and the average value was reported.

\section{Shore $D$ hardness analysis}

The Shore $D$ hardness of the samples was undertaken by using a Harteprufer Bareiss durometer according to ISO 868. The reported values of the hardness are averaged from five measurements on different parts of each specimen.

\section{Morphology analysis}


The morphologies of the fracture surfaces were observed by using a JEOL JSM-6360LV scanning electron microscope. The samples were fractured in liquid nitrogen. The chicken feather fibre was cut with scissors. The samples were coated with a thin layer of gold before scanning electron microscopy (SEM) examination.

\section{Thermogravimetric analysis}

The thermogravimetric analysis (TG) was performed in argon atmosphere using a TA(TGA Q50 V6.1 Build 181) instrument at a heating rate of $15^{\circ} \mathrm{C} / \mathrm{min}$, from 23 to $580^{\circ} \mathrm{C}$.

\section{Results And Discussion}

\section{Density Variation}

The influence of fibres on the density of the PVC composites is shown in Table 1. All PVC compositions filled with feather fibres have lower density compared to their matrix. Density decreased with increasing amounts of fibres. This can be accounted for the light weight of the chicken feather fibres $\left(0.89 \mathrm{~g} / \mathrm{cm}^{3}\right.$ as determined by Barone and Schmidt [9]). No natural or commercially available synthetic fibres today have a density as low as that of chicken feathers [7].

\section{Water Absorption}

The results of the percentages of water uptake in biocomposites are given in Table 2. The data shows that water absorption in the biocomposites is greater than the hydrophobic PVC matrix. It increases with increasing fibre content in the biocomposites. Moreover, the water uptake increased for all the samples when the temperature increased, because temperature accelerates the diffusion of water in the material.

This output comes from the following facts: 1) water is absorbed by the fibres in the composite, 2) the presence of voids or cracks or even poor matrix/fibre adhesion [21].

Chicken feather fibres remain susceptible to water absorption according to the amino acid sequence which reveals that keratin has about $40 \%$ hydrophilic chemical groups and $60 \%$ hydrophobic chemical groups in its structure [22]. The great water absorption in composites can be the result of their increased porosity, which facilitates the penetration and accumulation of water within the biocomposites. Porosity in natural fibre composites has been shown to increase with fibre content; it is one of the main factors affecting mechanical performance of natural fibre composites [23].

The water absorption characteristic depends on the content of the fibre, fibre orientation, temperature, area of the exposed surface, permeability of fibres, void content and the hydrophilicity of the individual components [24].

\section{Tensile Properties}


Figures 1-3 illustrate the effect of CFF and DIDP content on the tensile properties of PVC composites. According to Reddy and Yang [25],who determined that chicken feather barbs have strength of $180 \mathrm{MPa}$, elongation of $7.7 \%$ and a modulus of $4.7 \mathrm{GPa}$, it can be noticed that the strength and modulus of fibres are greater than that unfilled PVC(from Figures 1 and 3), so the CFF are stronger and stiffer than the matrix.

Figure 1 shows that increasing amounts of the fibre induces decrease in stress at break of the CFF reinforced biocomposites. Furthermore, the increased plasticizer content has also lowered the stress at break in both unfilled PVC and CFF/PVC composites, because of plasticization of the matrix. In general, at a higher plasticizer concentration (more than 15-20\%), the materials become softer and tougher, with a lower tensile strength, a lower modulus, and a higher elongation at break and a higher impact strength [26].

On the other hand, when fibre content increases, the elongation at break decreases as depicted in Figure 2. This shows that fibres make biocomposites more brittle; for, the presence of fibres in the matrix reduces the ability of the sample to deform by restricting the mobility of the polymer chains. As a consequence, it is difficult for the segments of the material to easily slip past each other [27].

Figure 3 shows that Young's modulus of each CFF/PVC biocomposite is higher than that of unfilled PVC, except for the formulations with 15 wt\% DIDP. On the other hand, the Young's modulus decreased significantly as the DIDP concentration increased. This indicates that CFF improve stiffness of PVC and the plasticizer reduces the rigidity of the composite.

This is a common behaviour for the polymers filled with natural fibres. Fillers are said to be much stiffer than the polymer matrix, and as a result, they add stiffness to the final product [28].

Similar behaviour was reported by several authors with different natural fillers in PVC composites [2831].The decrease in tensile strength with increasing amount of filler was attributed to the poor dispersion of the filler in the PVC matrix and the increase of interfacial defects or debonding between polymer and filler [27]. Moisture pick-up in the fibre was also expected to participate in decreasing the tensile strength [32].

Baba and Özmen [13] reported that Young's modulus of PLA reinforced CFF composites is higher, but their tensile strength and elongation at break are lower than pure PLA. In the case of polyethylene matrix, Barone and Schmidt [9] prepared polyethylene/CFF composites at a rate of 0-50 wt\%. These authors reported that the elastic modulus and yield stress increase as feather fibre loading increases. The yield strain decreases as fibre loading increases.

\section{Shore D hardness Evolution}

Table 3 shows that the Shore D hardness of composites enhanced upon addition of fibres. However, the hardness decreased with increasing plasticizer content for unfilled PVC and CFF/PVC biocomposites. It can be concluded that the rigidity of the composites is improved with the reinforcement of CFF. 


\section{Morphology analysis}

The SEM micrographs of a chicken feather fibre are presented in Figure 4 while the SEM micrographs of fractured surfaces of the 15/5, 15/15, 60/15 and 60/25 composites are shown in Figure 5.

Figure $4 \mathrm{~A}$ and $\mathrm{B}$ shows, respectively, barb and barbules. It can be seen that the barbules do not have a smooth surface and have hook-like structures along their surface. The cross-section of a feather fibre (Figure 4C) reveals a hollow structure. This latter makes barbs to be very light in weight [25]. The fibrillar surface of keratin fibre is evidenced by Figure 4D.

Barone and Schmidt [9] stated that the intrinsic surface roughness of the feather fibres increases the surface area by a factor of about 2.2 over a perfectly smooth fibre. The possibility of strong chemical compatibility and lots of available fibre surface area may increase the fibre/surface interactions over smooth inorganic fibres or cellulose-based fibres.

Figure 5D shows the presence of holes with same diameter of the fibres, which demonstrates that the fibres were pulled out from the matrix, probably because of a low adhesion between the fibre and the matrix. This is confirmed by Figure $5 \mathrm{~A}$ which reveals the presence of a gap between the matrix and the fibre. The insufficient adhesion may be caused by the hydrophilic groups of feather keratin $(40 \%)$ which have relatively low compatibility with the hydrophobic PVC matrix. It can be also attributed to the presence of water or ethanol residue used to clean the feathers. In addition to that, Figure 5B and C show the appearance of voids that represent the porosity.

However, there are some fibres that are still attached to the matrix, which implies the presence of a favourable interaction between the two phases, probably related to the hydrophobic groups of feather keratin $(60 \%)$ which are compatible with the polymer matrix.

From the images, it can be suggested that there is an interaction between the fibres and the polymer and that the fibres are moderately dispersed. Good fibre dispersion promotes good interfacial bonding, reducing voids by ensuring that fibres are fully surrounded by the matrix [23].

These micrographs could explain the decrease in stress at break of the composites by the porosity and the insufficient adhesion between the fibres and PVC matrix. Indeed, the observed gap limits the transfer of stress from the matrix to the fibres. It is also noticed that some fibres are not oriented parallel to the direction of the applied load, whereas the fibre reinforcing effect is most efficient along the fibre axis orientation [33].

\section{Thermogravimetric Analysis}

The thermal stability of CFF and CFF/PVC biocomposites was investigated by thermogravimetric (TG) and derivative thermogravimetric (DTG) analysis (Figure 6A and B). The corresponding data are given in Table 4. 
TG and DTG thermograms of chicken feather fibres display two steps of weight loss. The first one occurred up to $100^{\circ} \mathrm{C}$ with a weight loss of about $10 \%$. It characterizes evaporation of water and ethanol used to clean the feathers. The second step occurred from $200^{\circ} \mathrm{C}$ and characterizes decomposition of CFF. The weight loss was of about $70 \%$ with a maximum mass change at $323^{\circ} \mathrm{C}$.

Brebu and Spiridon [34] have identified the compounds resulting from the thermal degradation of keratin waste (sheep wool, human hair and chicken feathers), and found the following: inorganic gases $\left(\mathrm{NH}_{3}\right.$, $\mathrm{CO}_{2}, \mathrm{SCS}, \mathrm{SCO}, \mathrm{H}_{2} \mathrm{~S}$ and $\mathrm{SO}_{2}$ ), water, thiols, nitriles, aromatics, pyrroles, pyridines, amides, sulphides, thiazoles and thiophenes.

The TG curves of unfilled PVC and biocomposites are close to each other because PVC accounted for a high weight in biocomposites. The DTG curves of unfilled PVC and composites exhibit two decomposition peaks. The first indicates a loss of mass occurring above $200^{\circ} \mathrm{C}$ and the second above $400^{\circ} \mathrm{C}$. Concerning biocomposite materials, the first peak is attributed to the plasticizer migration and the release of $\mathrm{HCl}$ with some benzene traces [35] owing to the thermal degradation of PVC matrix, plus the degradation of keratin. The second peak corresponds to the polyacetylene cracking in PVC matrix [35].

As can be seen from the Figure 6, the thermal decomposition of the biocomposites starts before PVC matrix. The temperature at maximum weight loss in the first step is higher in biocomposites, due to the degradation of CFF at higher temperature, in contrast to the second step where the temperature is lower. Simultaneously, the speed of maximal weight loss is lower in biocomposites.

Additionally, the smooth TG curves correspond to the homogenous loss mass behaviour which indicates homogenous structure of composites [36].

\section{Conclusions}

The work presented in this paper shows the potential of fibres obtained from chicken feathers as a reinforcement of a polymer matrix (PVC). As a result, the addition of untreated CFF into PVC reduced the density of the product. The biocomposites exhibited more water absorption with respect to the PVC matrix. The stress and elongation at break decreased with the increase of CFF content. However, there was an increase of Young's modulus and Shore D hardness. With increased fibre amounts, the resulting biocomposites became more stiff and rigid while being more lightweight.TG analysis revealed that chicken feather fibres are thermally stable at the temperatures of PVC processing. Despite DIDP plasticizer reduced the tensile properties; it has improved the processability of CFF/PVC composites.

Finally, the results showed that chicken feather fibres can be used efficiently in the manufacture of biocomposite materials based on natural resources, and thus turning waste into resource.

\section{Declarations}

\section{Acknowledgements}


This work was supported by DGRSDT (Direction Générale de la Recherche Scientifique et du Développement Technologique, Algeria).

The authors would like to express their thanks to CABEL and CATEL companies located in Algiers (Algeria) for supplying materials used in this work.

\section{References}

1. Mohanty S, Nayak S K (2011) Biobased composites and applications. In: S. Kalia and L. Avérous (Eds) Biopolymers: Biomedical and environmental applications (Salem: Scrivener Publishing), 225266.

2. Graupner N, Müssig J (2010) Technical applications of natural fibres: An overview. In: J. Müssig (Ed.) Industrial applications of natural fibres: structure, properties and technical applications (Chichester: John Wiley \& Sons), 63-71.

3. Cheung H Y, Ho M P, Lau K T, Cardona F, Hui D (2009) Natural fibre-reinforced composites for bioengineering and environmental engineering applications Composites: Part B 40: 655-663.

4. Teresa K K, Justyna B (2011) Biodegradation of keratin waste: Theory and practical aspects Waste Management 31: 1689-1701.

5. Schmidt W F, Line M J (1996) Physical and chemical structures of poultry feather fibre fractions in fibre process development. In: TAPPI Proceedings: Nonwovens Conference; 135-140.

6. Fraser R D B, Mac Rae T P (1980) Molecular structure and mechanical properties of keratins. In: J.F.V. Vincent and J.D. Currey (Eds), Symposia of the Society for Experimental Biology 34 The Mechanical Properties of Biological Materials (Cambridge: Cambridge University Press), 211-246.

7. Tesfaye T, Sithole B, Ramjugernath D, Chunilall V (2017) Valorisation of chicken feathers: Characterisation of physical properties and morphological structure Journal of Cleaner Production 149: 349-365.

8. Barone J R, Schmidt W F, Liebner C F E (2005) Compounding and molding of polyethylene composites reinforced with keratin feather fibre Composites Science and Technology 65: 683-692.

9. Barone J R, Schmidt W F (2005) Polyethylene reinforced with keratin fibres obtained from chicken feathers Composites Science and Technology 65: 173-181.

10. Barone J R (2005) Polyethylene/keratin fibre composites with varying polyethylene crystallinity. Composites: Part A 36: 1518-1524.

11. Bullions T A, Hoffman D, Gillespie R A, Price-O'Brien J, Loos A C (2006) Contributions of feather fibres and various cellulose fibres to the mechanical properties of polypropylene matrix composites Composites Science and Technology 66: 102-114.

12. Cheng S, Lau K T, Liu T, Zhao Y, Lam P M, Yin Y (2009) Mechanical and thermal properties of chicken feather fibre/PLA green composites Composites: Part B40: 650-654. 
13. Baba B O, Özmen U (2017) Preparation and Mechanical Characterization of Chicken Feather/PLA Composites Polymer Composites 38: 837-845.

14. Martinez-Hernandez A L, Velasco-Santos C, de-lcaza M, Castano V M (2005) Mechanical properties evaluation of new composites with protein biofibres reinforcing poly(methyl methacrylate) Polymer 46: 8233-8238.

15. Martinez-Hernandez A L, Velasco-Santos C, de-Icaza M, Castano, V M (2007) Dynamical-mechanical and thermal analysis of polymeric composites reinforced with keratin biofibres from chicken feathers Composites: Part B 38: 405-410.

16. Flores-Hernandez C G, Colin-Cruz A, Velasco-Santos C, Castano V M, Rivera-Armenta J L, AlmendarezCamarillo A, Garcia-Casillas P E and Martinez-Hernandez A L (2014) All green composites from fully renewable biopolymers: Chitosan-starch reinforced with keratin from feathers Polymers 6: 686-705.

17. Hong C K, Wool R P (2005) Development of a bio-based composite material from soybean oil and keratin fibres Journal of Applied Polymer Science 95: 1524-1538.

18. Patrick S G (2005) Practical Guide to Polyvinyl Chloride (Shrewsbury: Rapra Technology).

19. Hassan A, Salema A A, Ani F N, Bakar A A (2010) A review on oil palm empty fruit bunch fibrereinforced polymer composite materials Polymer Composites 31: 2079-2101.

20. Gassner G, Schmidt W, Line M J, Thomas C, Waters R M (1998) Fibre and fibre products produced from feathers. Patent 5,705,030, USA.

21. Kiani H, Ashori A, Mozaffari S A (2011) Water resistance and thermal stability of hybrid lignocellulosic filler-PVC composites Polymer Bulletin 66: 797-802.

22. Barone J R, Schmidt W F (2006) Effect of formic acid exposure on keratin fibre derived from poultry feather biomass Bioresource Technology 97: 233-242.

23. Pickering K L, Aruan Efendy M G, Le T M (2016) A review of recent developments in natural fibre composites and their mechanical performance Composites: Part A 83: 98-112.

24. Nosbi N, Akil H M, Mohd Ishak Z A, Abu Bakar A (2010) Degradation of compressive properties of pultruded kenaf fibre reinforced composites after immersion in various solutions Materials and Design 31: 4960-4964.

25. Reddy N, Yang Y (2007) Structure and properties of chicken feather barbs as natural protein fibres Journal of Polymers and the Environment 15: 81-87.

26. Matuana L M, Park C B, Balatinecz J J (1997) The effect of low levels of plasticizer on the rheological and mechanical properties of polyvinyl chloride/newsprint-fibre composites Journal of Vinyl \& Additive Technology 3: 265-273.

27. Saini G, Bhardwaj R, Choudhary V, Narula A K (2010) Poly(vinyl chloride)-acacia bark flour composite: Effect of particle size and filler content on mechanical, thermal, and morphological characteristics Journal of Applied Polymer Science 117: 1309-1318.

28. Saini G, Choudhary V, Bhardwaj R, Narula A K (2008) Study on PVC composites containing Eugenia jambolana wood flour Journal of Applied Polymer Science 107: 2171-2179. 
29. Djidjelli H, Boukerrou A, Rabouhi A, Founas R, Kaci M, Zefouni O, Djillali N, Belmouhoub L (2008) Effect of olive residue benzylation on the thermal and mechanical properties of poly(vinyl chloride)/olive residue composites Journal of Applied Polymer Science 107: 1459-1465.

30. Ge X C, Li X H, Meng Y Z (2004) Tensile properties, morphology, and thermal behaviour of PVC composites containing pine flour and bamboo flour Journal of Applied Polymer Science 93: 18041811.

31. Crespo J E, Sanchez L, Garcia D, Lopez J (2008) Study of the mechanical and morphological properties of plasticized PVC composites containing rice husk fillers Journal of Reinforced Plastics and Composites 27: 229-243.

32. Sombatsompop N, Chaochanchaikul K, Phromchirasuk C, Thongsang S (2003) Effect of wood sawdust content on rheological and structural changes, and thermo-mechanical properties of PVC/sawdust composites Polymer International 52: 1847-1855.

33. Herrera-Franco P J, Valadez-Gonzalez A (2005) A study of the mechanical properties of short naturalfibre reinforced composites Composites: Part B 36: 597-608.

34. Brebu M, Spiridon I (2011) Thermal degradation of keratin waste Journal of Analytical and Applied Pyrolysis 91: 288-295.

35. Djidjelli H, Sadoun T, Benachour D (2000) Effect of plasticizer nature and content on the PVC stability and dielectric properties Journal of Applied Polymer Science 78: 685-691.

36. Özmen U, Baba B O (2017) Thermal characterization of chicken feather/PLA biocomposites. Journal of Thermal Analysis and Calorimetry 129: 347-355.

\section{Tables}

Table1. Density of PVC and biocomposite materials.

\begin{tabular}{|lllll|}
\hline \multicolumn{5}{|c|}{ Plasticizer (wt\%) } \\
\hline Fibres (wt\%) & 15 & 30 & 45 & 60 \\
\hline 0 & $1.27 \pm 0.02$ & $1.21 \pm 0.03$ & $1.21 \pm 0.01$ & $1.17 \pm 0.01$ \\
5 & $1.26 \pm 0.01$ & $1.19 \pm 0.03$ & $1.18 \pm 0.02$ & $1.15 \pm 0.01$ \\
10 & $1.21 \pm 0.01$ & $1.21 \pm 0.01$ & $1.17 \pm 0.01$ & $1.17 \pm 0.01$ \\
15 & $1.18 \pm 0.03$ & $1.17 \pm 0.02$ & $1.12 \pm 0.02$ & $1.15 \pm 0.01$ \\
20 & - & - & - & $1.16 \pm 0.00$ \\
25 & - & - & - & $1.14 \pm 0.01$ \\
\hline
\end{tabular}

Table 2. Percentages of water uptake in CFF/PVC biocomposites (\%). 


\begin{tabular}{|llll|}
\hline Sample & Water at $23^{\circ} \mathrm{C}$ & \multicolumn{2}{l}{ Water at $60^{\circ} \mathrm{C}$} \\
\cline { 3 - 4 } DIDP/CFF & After $24 \mathrm{~h}$ & After & After \\
& & $30 \mathrm{~min}$ & $24 \mathrm{~h}$ \\
\hline $15 / 0$ & $0.08 \pm 0.00$ & $0.06 \pm 0.01$ & $0.60 \pm 0.02$ \\
\hline $15 / 5$ & $0.31 \pm 0.02$ & $0.33 \pm 0.06$ & $1.83 \pm 0.06$ \\
\hline $15 / 10$ & $0.53 \pm 0.01$ & $0.51 \pm 0.04$ & $2.34 \pm 0.05$ \\
\hline $15 / 15$ & $0.87 \pm 0.01$ & $0.76 \pm 0.08$ & $3.33 \pm 0.01$ \\
\hline $30 / 0$ & $0.10 \pm 0.02$ & $0.22 \pm 0.01$ & $0.91 \pm 0.03$ \\
\hline $30 / 5$ & $0.43 \pm 0.03$ & $0.30 \pm 0.01$ & $1.93 \pm 0.03$ \\
\hline $30 / 10$ & $0.71 \pm 0.03$ & $0.53 \pm 0.06$ & $2.56 \pm 0.08$ \\
\hline $30 / 15$ & $0.87 \pm 0.02$ & $0.69 \pm 0.04$ & $3.48 \pm 0.07$ \\
\hline $45 / 0$ & $0.10 \pm 0.02$ & $0.19 \pm 0.04$ & $0.94 \pm 0.03$ \\
\hline $45 / 5$ & $0.46 \pm 0.00$ & $0.34 \pm 0.01$ & $1.96 \pm 0.01$ \\
\hline $45 / 10$ & $0.66 \pm 0.02$ & $0.46 \pm 0.01$ & $2.58 \pm 0.07$ \\
\hline $45 / 15$ & $0.97 \pm 0.01$ & $0.62 \pm 0.01$ & $3.45 \pm 0.03$ \\
\hline $60 / 0$ & $0.13 \pm 0.02$ & $0.16 \pm 0.01$ & $1.15 \pm 0.03$ \\
\hline $60 / 5$ & $0.50 \pm 0.01$ & $0.39 \pm 0.03$ & $2.13 \pm 0.02$ \\
\hline $60 / 10$ & $0.70 \pm 0.05$ & $0.50 \pm 0.02$ & $3.05 \pm 0.04$ \\
\hline $60 / 15$ & $0.94 \pm 0.02$ & $0.59 \pm 0.05$ & $3.50 \pm 0.04$ \\
\hline $60 / 20$ & $1.39 \pm 0.05$ & $0.87 \pm 0.05$ & $4.35 \pm 0.06$ \\
\hline $60 / 25$ & $1.57 \pm 0.02$ & $0.91 \pm 0.07$ & $4.67 \pm 0.20$ \\
\hline & & & \\
\hline & & & \\
\hline
\end{tabular}

Table 3. Variations of Shore D hardness of CFF/PVC biocomposites with fibres and plasticizer contents. 


\begin{tabular}{|lllll|}
\hline \multicolumn{5}{|c|}{ Plasticizer } \\
Fibres & 15 & 30 & 45 & 60 \\
\cline { 2 - 5 } 0 & $72.8 \pm 0.9$ & $61.8 \pm 0.2$ & $44.6 \pm 0.2$ & $34 \pm 0.5$ \\
\hline 5 & $74.6 \pm 0.6$ & $63.2 \pm 0.4$ & $47.4 \pm 0.2$ & $35.6 \pm 0.2$ \\
10 & $74.6 \pm 0.9$ & $63.8 \pm 0.2$ & $47.6 \pm 1.0$ & $42 \pm 0.0$ \\
15 & $75 \pm 0.5$ & $63 \pm 0.3$ & $51.8 \pm 0.2$ & $42 \pm 0.5$ \\
20 & - & - & - & $45.6 \pm 0.2$ \\
\hline 25 & - & - & - & $47.2 \pm 0.2$ \\
\hline
\end{tabular}

Table 4. TG and DTG results for CFF, PVC matrix and CFF/PVC biocomposites.

\begin{tabular}{|llllllllll|}
\hline Sample & \multicolumn{1}{c}{ Stage 1 } & \multicolumn{7}{c|}{ Stage 2 } \\
\hline & $\mathrm{W}_{1}$ & $\mathrm{~T}_{\mathrm{m} 1}$ & $\mathrm{v}_{\mathrm{m} 1}$ & $\mathrm{~T}_{\mathrm{m} 1}^{\prime}$ & $\mathrm{v}_{\mathrm{m} 1}^{\prime}$ & $\mathrm{W}_{2}$ & $\mathrm{~T}_{\mathrm{m} 2}$ & $\mathrm{v}_{\mathrm{m} 2}$ & $\mathrm{R}$ \\
\hline CFF & 9.92 & $/$ & $/$ & $/$ & $/$ & 69.91 & 323.25 & 8.73 & 20.17 \\
\hline $15 / 0$ & 62.22 & 280.77 & 25.62 & 297.7 & 22.97 & 20.15 & 459.16 & 7.11 & 17.63 \\
\hline $15 / 15$ & 65.03 & 283.15 & 24.94 & $/$ & $/$ & 21.15 & 444.25 & 4.44 & 13.82 \\
\hline $60 / 0$ & 71.75 & 282.85 & 31.53 & 299.3 & 21.53 & 15.11 & 458.36 & 4.68 & 13.14 \\
\hline $60 / 20$ & 72.47 & 285.90 & 25.08 & $/$ & $/$ & 16.5 & 454.36 & 3.51 & 11.03 \\
\hline
\end{tabular}

W: weight loss (\%). $\mathrm{T}_{\mathrm{m}}$ : temperature of maximum weight loss $\left({ }^{\circ} \mathrm{C}\right) . \mathrm{v}_{\mathrm{m}}$ :Speed of maximal weight loss (\%/min). R: Residual mass (\%).

\section{Figures}




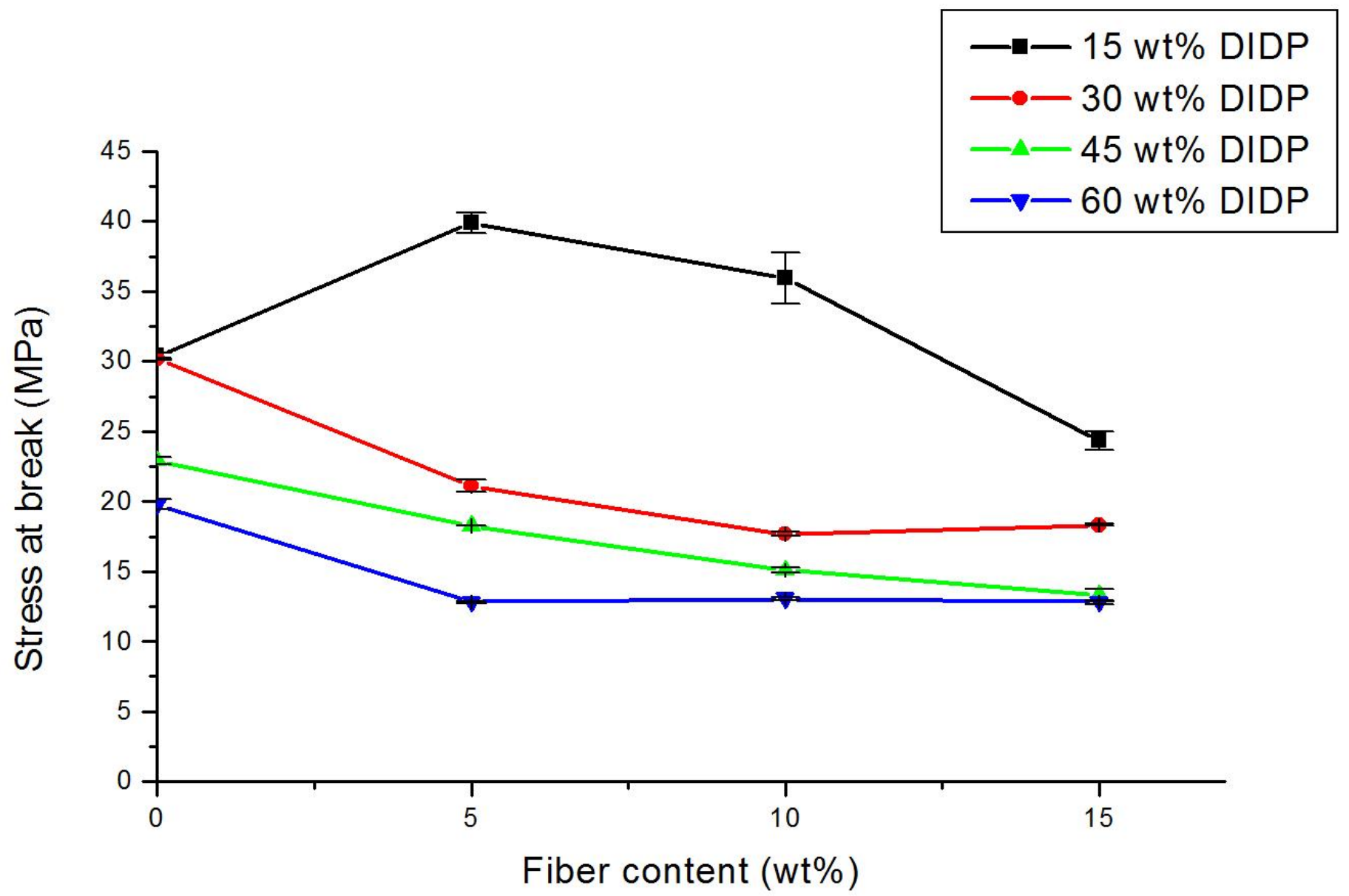

Figure 1

Influence of chicken feather fibre content on the stress at break of PVC. 


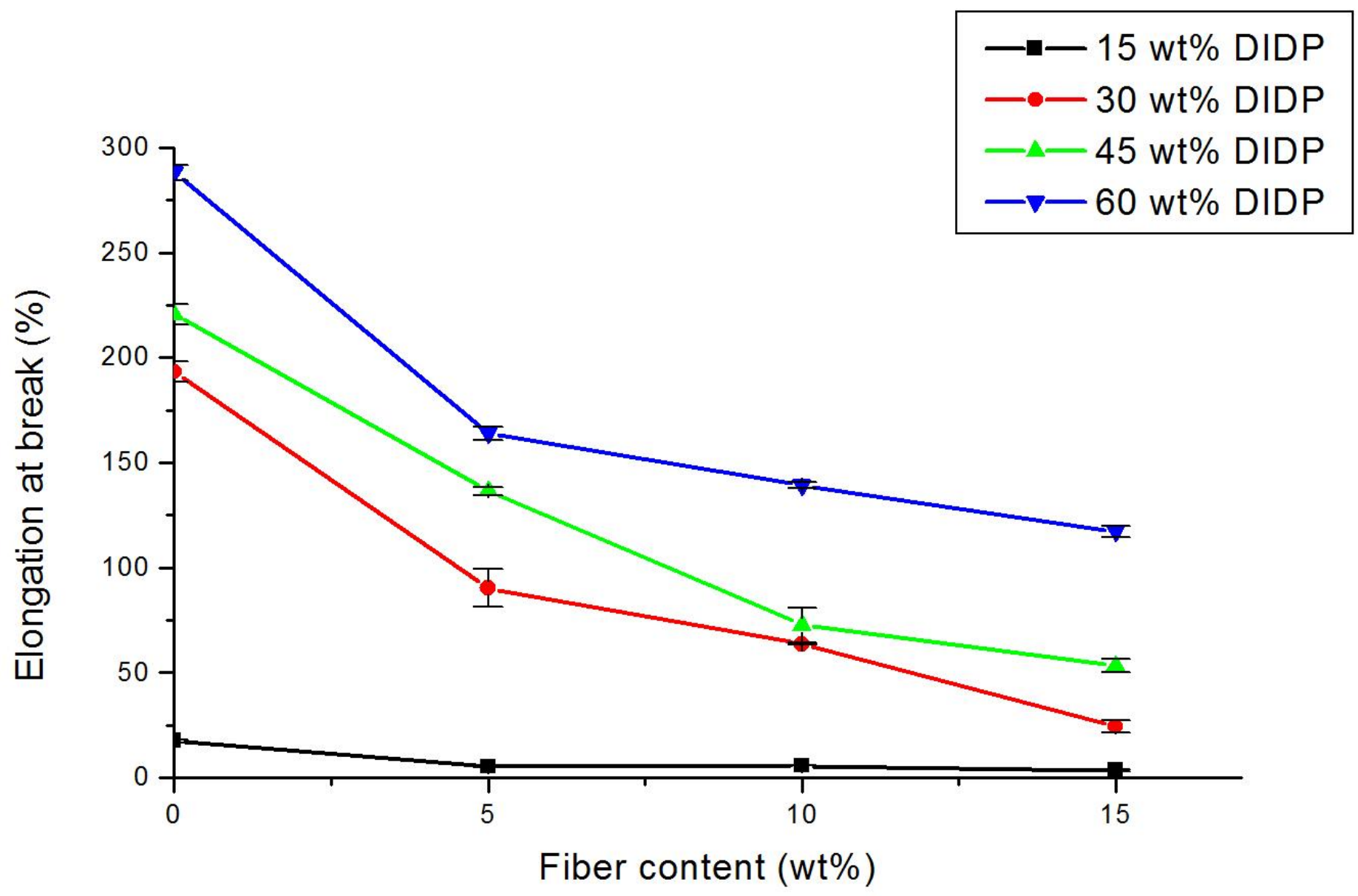

Figure 2

Variations of elongation at break for CFF/PVC composites with chicken feather fibre content. 


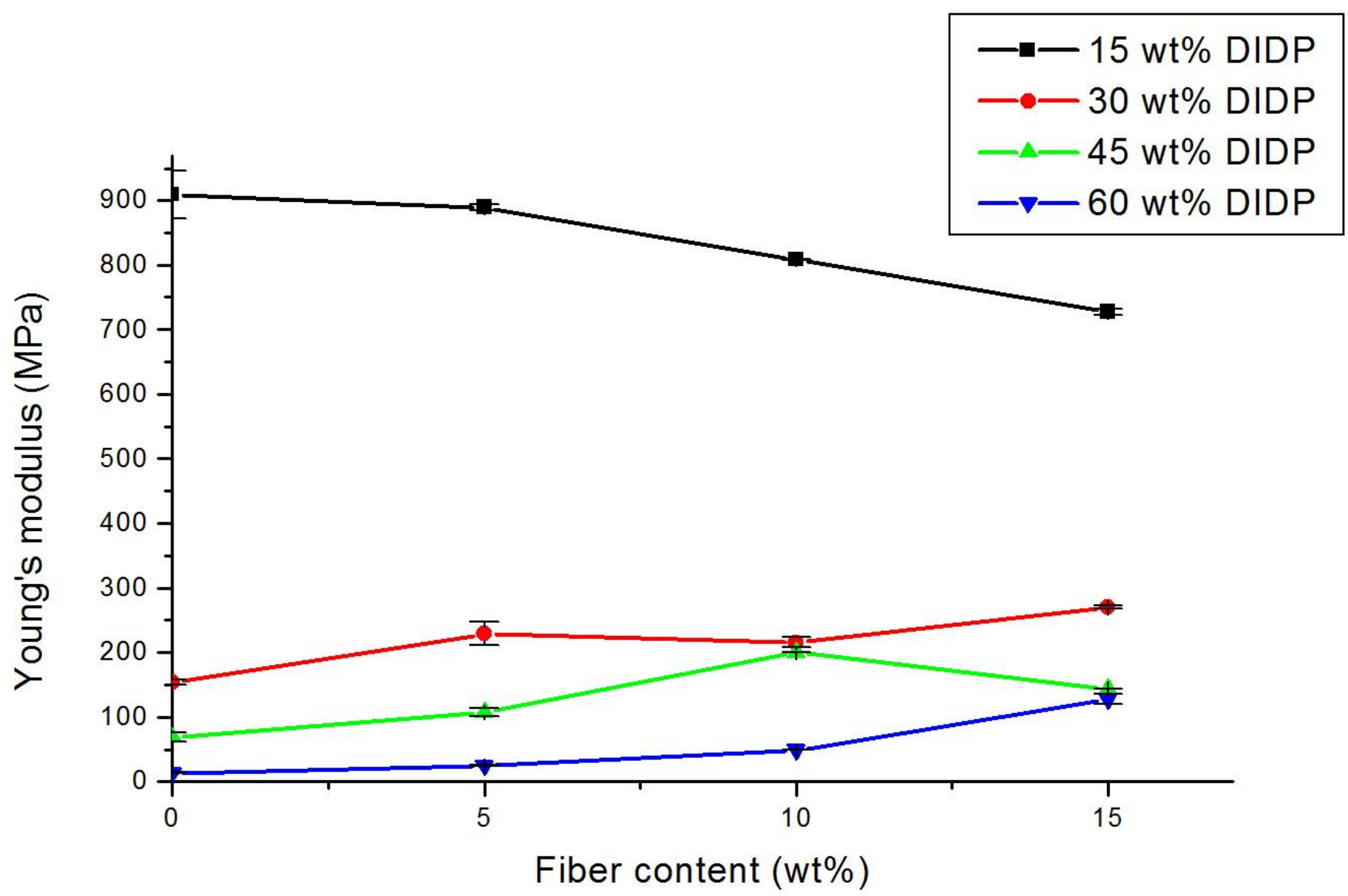

Figure 3

Effect of fibre content on the Young's modulus of CFF/PVC composites. 

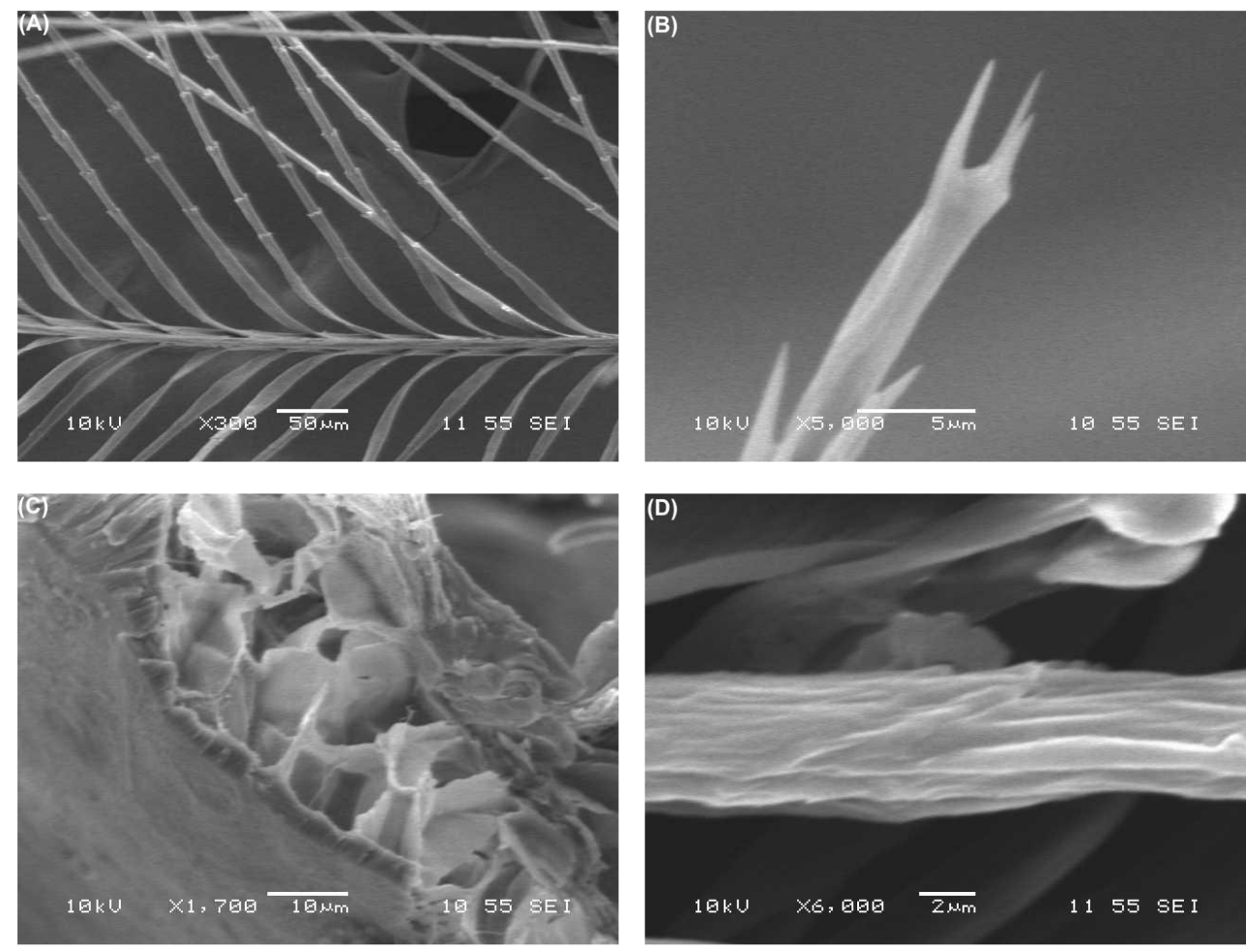

Figure 4

Morphological structures of chicken feather fibre. 

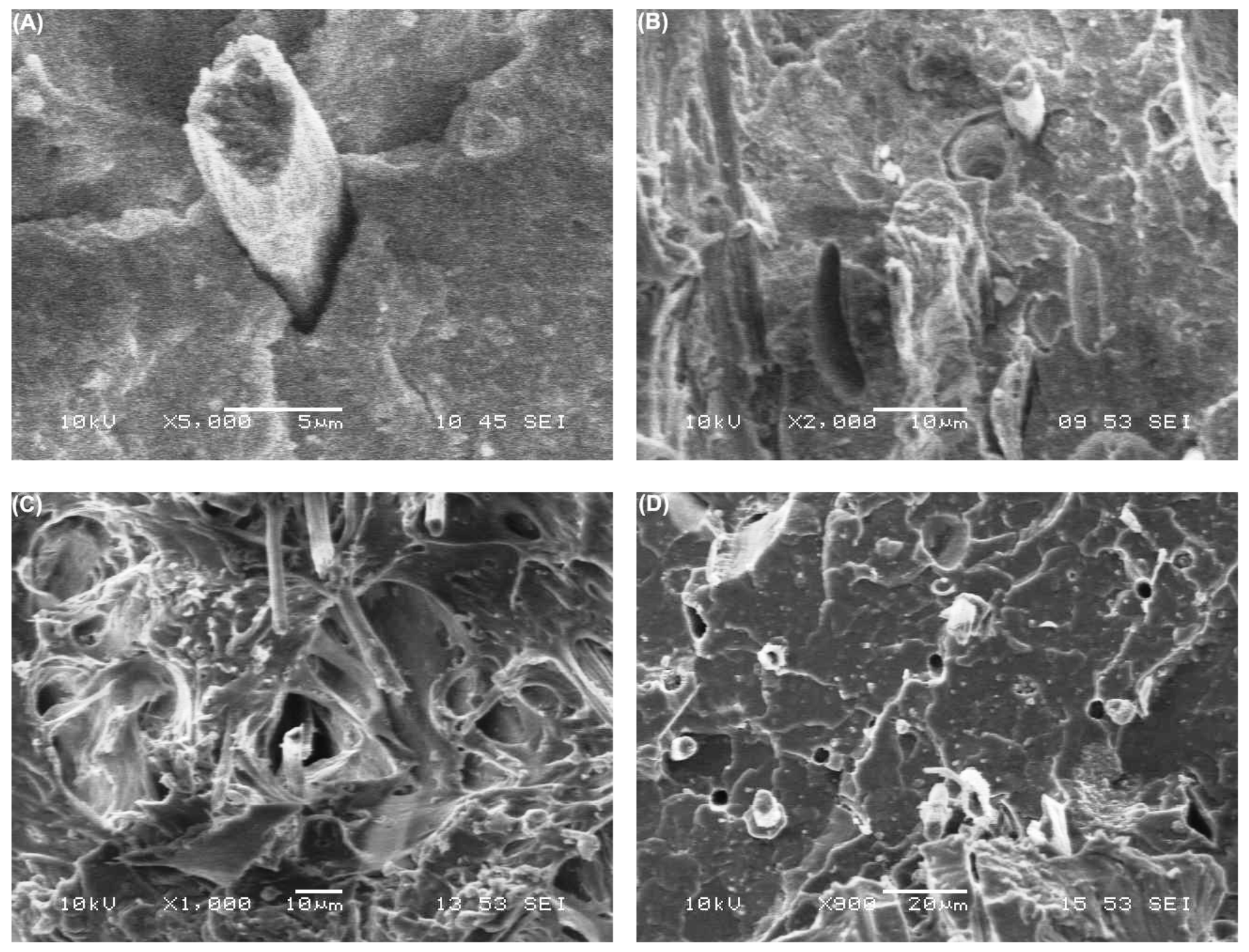

\section{Figure 5}

Fracture surfaces in SEM of CFF/PVC composites: (A) 15/5, (B) 15/15, (C) 60/15, (D) 60/25.
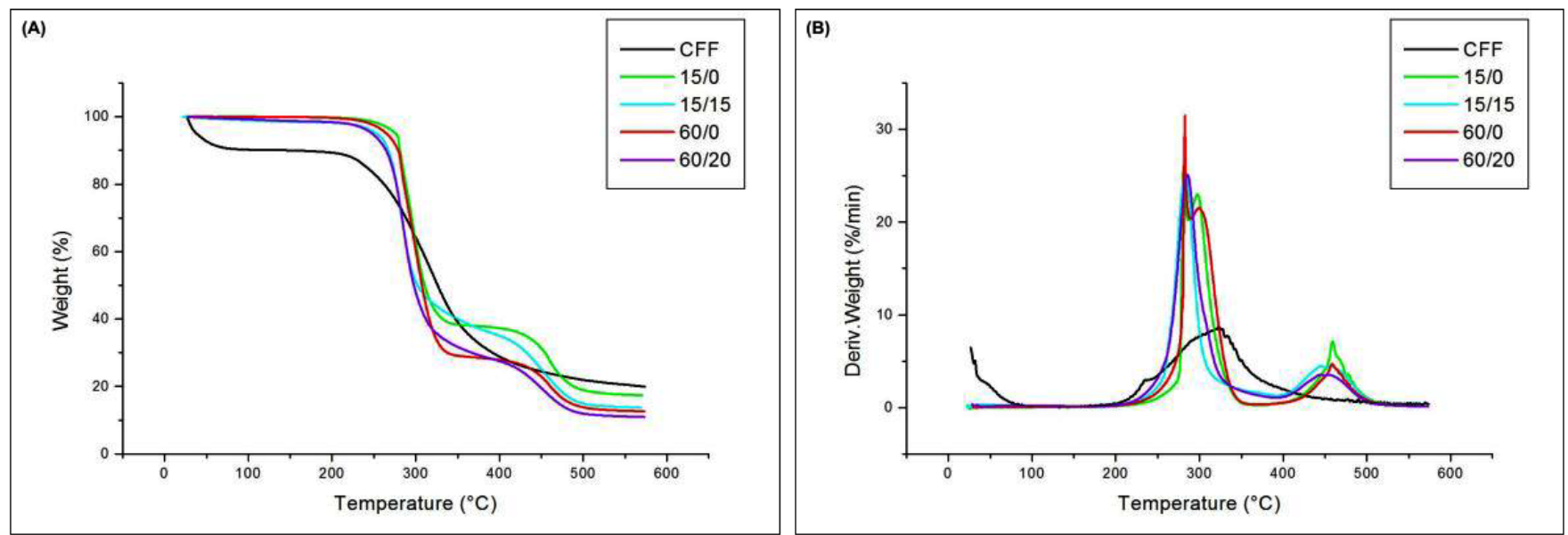
Figure 6

TG (A) and DTG (B) curves of CFF, unfilled PVC and biocomposites. 